\title{
Delamination crack initiation from copper/silicon nitride interface edge with nanoscale singular stress field
}

\section{AUTHOR(S):}

Kawai, Emi; Sanada, Kazunori; Sumigawa, Takashi; Kitamura, Takayuki

\section{CITATION:}

Kawai, Emi ... [et al]. Delamination crack initiation from copper/silicon nitride interface edge with nanoscale singular stress field. Engineering Fracture Mechanics 2014, 120: 6066

\section{ISSUE DATE:}

2014-04

URL:

http://hdl.handle.net/2433/187746

\section{RIGHT:}

(C) 2014 Elsevier Ltd.; This is not the published version. Please cite only the published version.; この論文は出版社版でありません。引用の際に は出版社版をご確認ご利用ください。 


\title{
Delamination crack initiation from \\ copper/silicon nitride interface edge with nanoscale singular stress field
}

\author{
Emi Kawai*, Kazunori Sanada, Takashi Sumigawa, Takayuki Kitamura \\ Department of Mechanical Engineering and Science, Graduate School of Engineering, Kyoto University, Kyoto University-Katsura, \\ Nishikyo-ku, Kyoto, 615-8540, Japan
}

\begin{abstract}
In order to investigate delamination crack initiation from an interfacial edge in nanoscale component with the singular stress field, we conduct mechanical experiments using four kinds of cantilever specimens with the nanoscale singular stress field at the copper/silicon nitride interface. The results reveal that regardless of the specimen dimensions, the critical magnitude of the plastic stress intensity parameter,

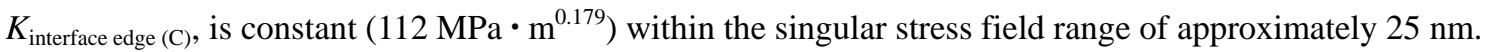
This indicates that in the nano-sized component, a delamination crack initiation is dominated by a nanoscale singular stress field near the interface edge.
\end{abstract}

Keywords: nanoscale, singular stress field, dissimilar interface, delamination crack initiation

\section{Introduction}

In multilayered components, stress is concentrated at the interface under load due to the deformation mismatch of dissimilar materials [1-3]. In particular, the singular stress field often appears near an interface edge where the interface meets a surface (Free edge effect) [4,5]. Therefore, the interface edge is one of the potential crack initiation sites. Once a delamination crack is initiated in the nano-sized component, it immediately leads to malfunction or facture. Thus, it is important to investigate the criterion for the delamination crack initiation from the interface edge.

In a bulk material, it is well known that the stress intensity factor $K$ can be applied to the criterion for the interfacial crack propagation [6-9]. At the interface edge, the singular stress field is governed by the stress

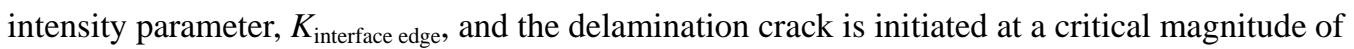

$K_{\text {interface edge }}$ in bulk materials [10-13]. These concepts are based on the continuum mechanics where the singular stress field contains of sufficient number of atoms. As the component size shrinks, the singular stress region near the interface edge is reduced to a nanometer scale [14, 15], which correspond to about several dozen to hundred atoms. In this case, it is not experimentally investigated well whether the delamination crack initiation is governed by the nanoscale singular stress field near the interface edge or not. 
The aim of this search is to investigate the criterion for the delamination crack initiation from the $\mathrm{Cu} / \mathrm{SiN}$ interface edge in nanoscale component on the basis of in situ experimental observation.

\section{Nomenclature}

\begin{tabular}{|ll|}
\hline$C_{11}, C_{12}, C_{44}$ & elastic constants for $\mathrm{Si}$ \\
$P_{\text {crack initiation }}$ & crack initiation load \\
$\Lambda_{\mathrm{K}}$ & magnitude of singular stress field \\
$K_{\text {interface edge }}$ & stress intensity parameter \\
$K_{\text {interface edge (C) }}$ & critical magnitude of plastic stress \\
& intensity parameter \\
$\sigma$ & von Mises stress \\
$\varepsilon$ & von Mises strain \\
$\lambda$ & order of the stress singularity \\
TEM & transmission electron microscopy \\
FEM & finite element method \\
SEM & scanning electron microscopy \\
FIB & focused ion beam \\
\hline
\end{tabular}

\section{Experiment and analysis}

\subsection{Specimen}

The material is multilayered $(\mathrm{Ti} / \mathrm{Cu} / \mathrm{SiN})$ thin films formed on a silicon substrate. Titanium (Ti) is deposited up to a thickness of a few nanometers at the rate of $20 \mathrm{~nm} / \mathrm{min}$ on Si wafer with (100) oriented before a $\mathrm{Cu}$ layer is deposited up to a thickness of $200 \mathrm{~nm}$ at the rate of $25 \mathrm{~nm} / \mathrm{min}$ by magnetron sputtering. A silicon nitride (SiN) layer is sequentially deposited up to a thickness of $900 \mathrm{~nm}$ at the rate of $11 \mathrm{~nm} / \mathrm{min}$ by magnetron sputtering without breaking the vacuum. As the interfacial strength between $\mathrm{Si}$ and $\mathrm{Cu}$ is increased by deposing the thin Ti layer, the delamination crack appears at the $\mathrm{Cu} / \mathrm{SiN}$ interface. Figure 1 illustrates the preparation procedure of the nanoscale cantilever specimens. A $10 \mu \mathrm{m} \times 10 \mu \mathrm{m} \times$ $10 \mu \mathrm{m}$ block is cut from the multilayered material (Fig. 1(a)) and is picked up by a probe manipulator (Fig. 1(b)). After the block is mounted on the top of a gold (Au) wire $(\varphi 0.25 \mathrm{~mm})$ with a flat top using an wolfram (W) deposition (Fig. 1(c)), the block is thinned in $z$ direction (Fig. 1(d)) and the cantilever specimen containing the $\mathrm{Si} / \mathrm{Ti} / \mathrm{Cu} / \mathrm{SiN}$ interfaces is processed by a focused ion beam (FIB: FB-2100FIB system (HITACHI)) (Fig. 1(e)). The gallium (Ga) ion beam energy is $40 \mathrm{kV}$, and the beam current is changed from $10 \mathrm{pA}$ to $10 \mathrm{nA}$ depending on the fabrication precision. 
Figure 2 schematically shows illustrations (a) and dimensions (b) of the cantilever-specimen, along with the loading scheme for the investigation of cracking behavior at the $\mathrm{Cu} / \mathrm{SiN}$ interface edge. Four specimens (Specimens 1, 2, 3, and 4) of different sizes, as summarized in Table 1, are prepared.

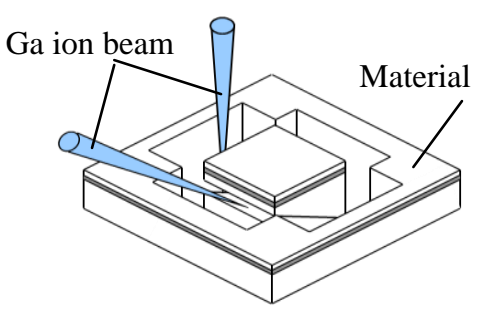

(a)

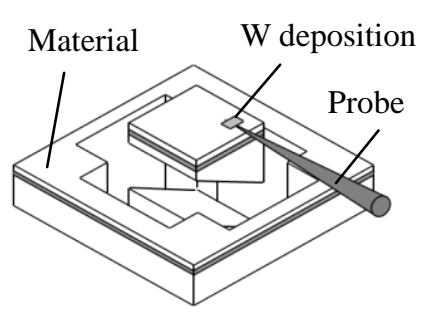

(b)

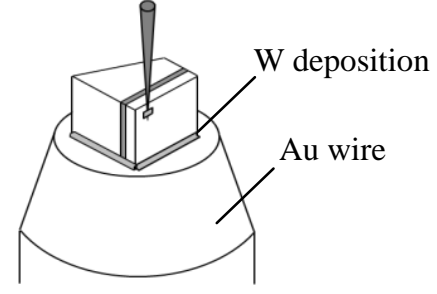

(c)

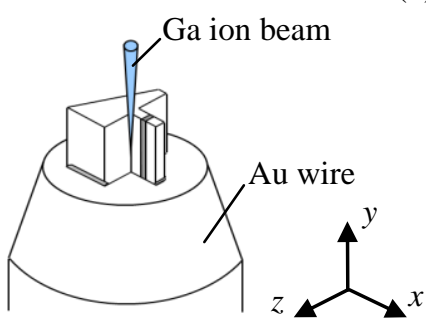

(d)

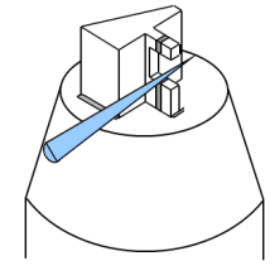

(e)

Fig. 1. Schematic illustration of preparation procedure of the nanoscale cantilever specimen.

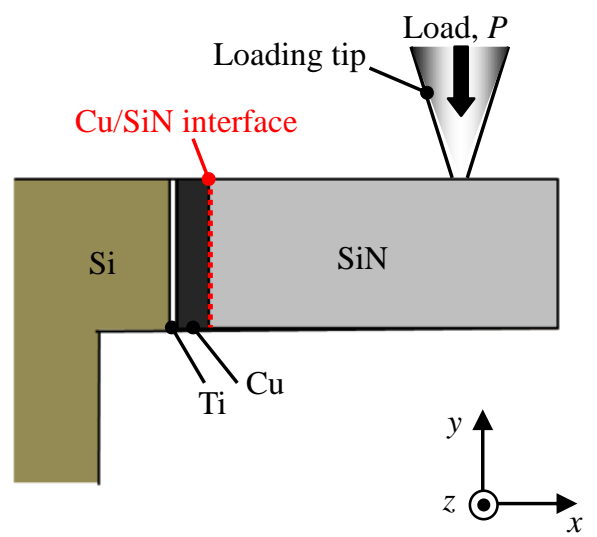

(a)

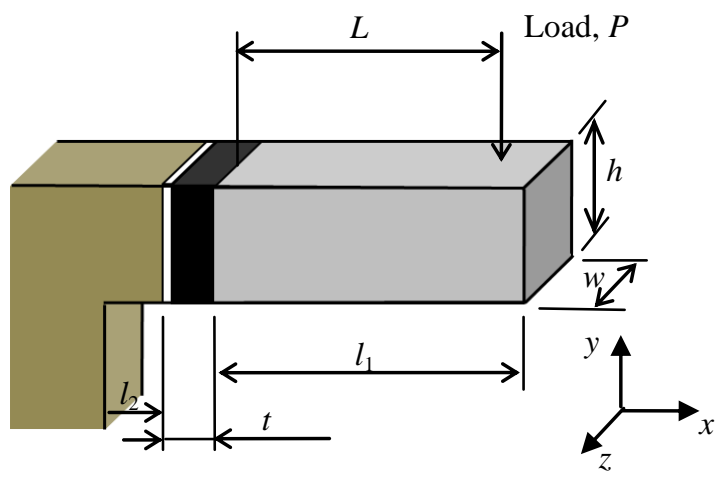

(b)

Fig. 2. Schematic illustration (a) and dimensions (b) of the nanoscale cantilever specimen. 
Table 1 Specimen size.

\begin{tabular}{|c|c|c|c|c|c|c|}
\hline Specimen & $\begin{array}{l}\text { Height } \\
h(\mathrm{~nm})\end{array}$ & $\begin{array}{l}\text { Width } \\
w(\mathrm{~nm})\end{array}$ & $\begin{array}{l}\text { Length of } \mathrm{SiN} \\
l_{1}(\mathrm{~nm})\end{array}$ & $\begin{array}{l}\text { Length of Si } \\
l_{2}(\mathrm{~nm})\end{array}$ & $\begin{array}{l}\text { Thickness of } \\
\mathrm{Cu} \text { and Ti thin } \\
\text { film } t(\mathrm{~nm})\end{array}$ & $\begin{array}{l}\text { Distance from the } \\
\text { loading point to } \\
\mathrm{Cu} / \mathrm{SiN} \text { interface } \\
L(\mathrm{~nm})\end{array}$ \\
\hline 1 & 700 & 665 & 897 & 308 & 205 & 750 \\
\hline 2 & 300 & 670 & 888 & 298 & 200 & 755 \\
\hline 3 & 250 & 685 & 896 & 286 & 198 & 785 \\
\hline 4 & 170 & 786 & 929 & 301 & 193 & 859 \\
\hline
\end{tabular}

\subsection{Loading method}

Figure 3 shows the minute mechanical loading apparatus (Nanofactory Instruments AB,SA2000N) used in this study. The loading apparatus, which is built into a transmission electron microscopy (TEM) holder, consists of a movable sample stage and a diamond loading tip with a load sensor. The measurement range and accuracy of the loading are $0-1000 \mu \mathrm{N}$ and $\pm 0.1 \mu \mathrm{N}$, respectively. The Au wire, on which a cantilever specimen is mounted, is attached to the stage which is three-dimensionally actuated by a piezoelectric actuator. The alignment resolution of the piezoelectric actuator in each direction $(x, y$ and $z)$ is approximately $1 \mathrm{~nm}$. In order to observe the cracking behavior, the experiments are conducted in TEM (JEOL Ltd. JEM-2100) with an acceleration voltage of $200 \mathrm{kV}$ under a $2.0 \times 10^{-5} \mathrm{~Pa}$ vacuum. The TEM image of the cantilever beam is continuously recorded using a digital camera (Gatan Inc, ES500) at the frame rate of $60 \mathrm{~Hz}$.

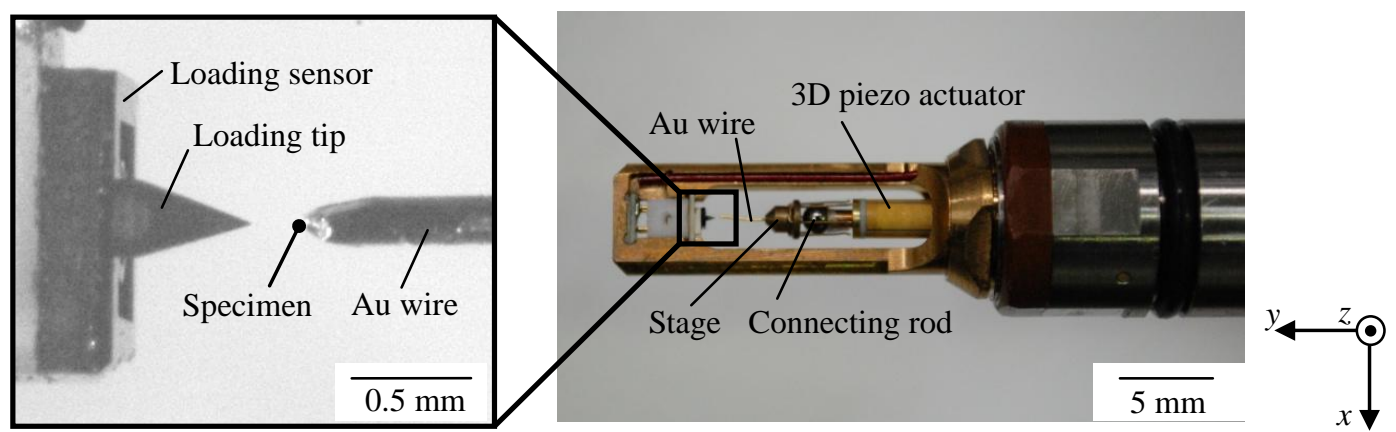

Fig. 3. Mechanical loading apparatus built into a TEM holder. 


\subsection{Analytical procedure}

The stress in the specimen is analyzed by a finite element method (FEM), in which an individual model is prepared for each experimental specimen, reproducing the shape on the basis of a 3D analysis of a scanning electron microscopy (SEM) and TEM micrographs. Figure 4 shows the representative analytical model (Specimen 1). Here, the Ti layer is not considered in this analysis model because the thickness is much thinner than that of other layers and it affects little on the stress distribution along the $\mathrm{Cu} / \mathrm{SiN}$ interface. (The difference between models with and without the Ti layer is approximately $0.02 \%$ at elastic analysis.) The regions near the interfaces $(\mathrm{Si} / \mathrm{Cu}$ and $\mathrm{Cu} / \mathrm{SiN})$, where the stress concentration is expected, are divided into a finer mesh. The perfect constraint condition is imposed on the back and the bottom ends of the model. The $\mathrm{Si}$ and $\mathrm{SiN}$ are treated as the elastic materials because the yield stress of them is specifically high. Tables 2 and 3 show the elastic constants of the component materials. Because the yield stress for the $\mathrm{Cu}$ thin film is lower than those for the Si substrate and SiN layer, the $\mathrm{Cu}$ thin film is treated as an elasto-plastic material. The elasto-plastic constitutive equation for the film is given by [16]:

$\sigma=\left\{\begin{array}{l}129000, \text { for } \sigma \leq 223(\mathrm{MPa}) \\ 2106 \varepsilon^{0.35}, \text { for } \sigma \geq 223(\mathrm{MPa})\end{array}\right.$

Here, $\sigma$ and $\varepsilon$ are the von Mises stress and strain, respectively.

The residual stresses of the $\mathrm{Cu}$ and $\mathrm{SiN}$ layers are measured experimentally in a previous paper $\left(\sigma_{\mathrm{Cu}}=\right.$ $147 \mathrm{MPa}, \sigma_{\mathrm{SiN}}=-290 \mathrm{MPa}$ ) [16]. The residual stresses are included in the FEM (ABAQUS, ver.6.5-6) calculations because they strongly affect on the stress state near the interfaces.

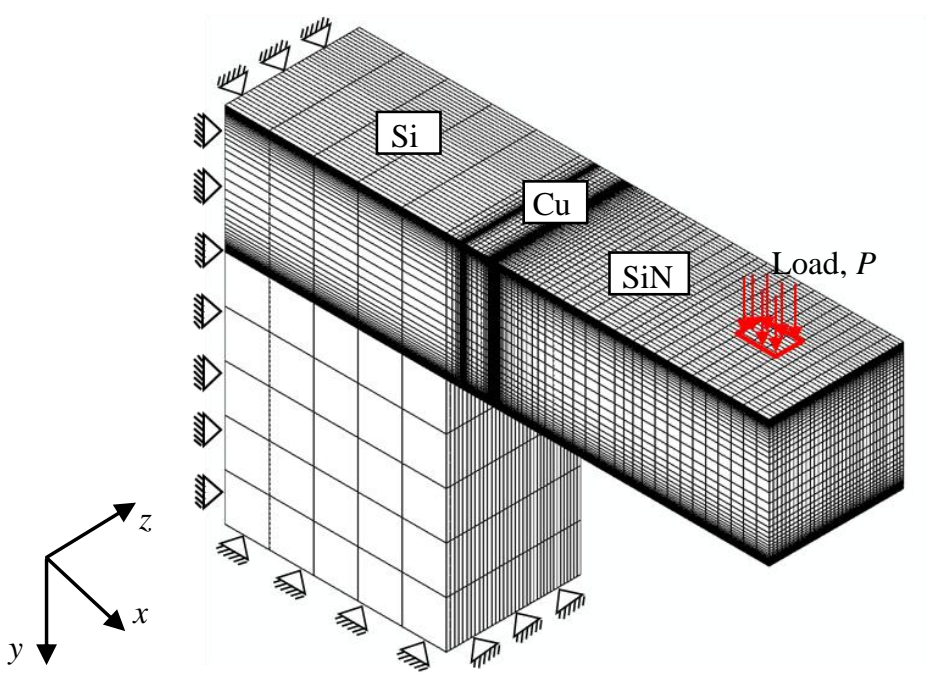

Fig. 4. Finite element analysis model of Specimen 1. 
Table 2 Elastic constants for the component materials $(\mathrm{Cu}, \mathrm{SiN})$.

\begin{tabular}{lll}
\hline Material & Young's modulus $E(\mathrm{GPa})$ & Poisson's ratio $v$ \\
\hline $\mathrm{Cu}$ & 129 & 0.34 \\
$\mathrm{SiN}$ & 197 & 0.27 \\
\hline
\end{tabular}

Table 3 Elastic constants for the component material ( $\mathrm{Si})$.

\begin{tabular}{llll}
\hline Material & $C_{11}(\mathrm{GPa})$ & $C_{12}(\mathrm{GPa})$ & $C_{44}(\mathrm{GPa})$ \\
\hline $\mathrm{Si}$ & 167.4 & 65.2 & 79.6
\end{tabular}

\section{Results and discussion}

\subsection{Critical load}

Figure 5 shows the load $(P)$ - time $(t)$ relationship for Specimen 1 and the TEM images corresponding to points A-C in Fig. 5. The load, $P$, monotonically increases up to a peak of $173 \mu \mathrm{N}$ (point B) and then suddenly drops to $0 \mu \mathrm{N}$ (point $\mathrm{C}$ ). The magnified view of the $\mathrm{Cu} / \mathrm{SiN}$ interface edge shows no precursory crack formation at point $\mathrm{B}$. This means that the crack initiates at the point $\mathrm{B}$ at the top of the $\mathrm{Cu} / \mathrm{SiN}$ interface edge and instantly propagated along the interface. Similar behavior is observed in the other

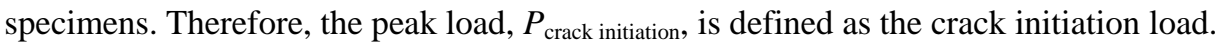

Table 4 shows a comparison of the crack initiation load at each specimen, and indicates that $P_{\text {crack initiation }}$ is increased with specimen height.

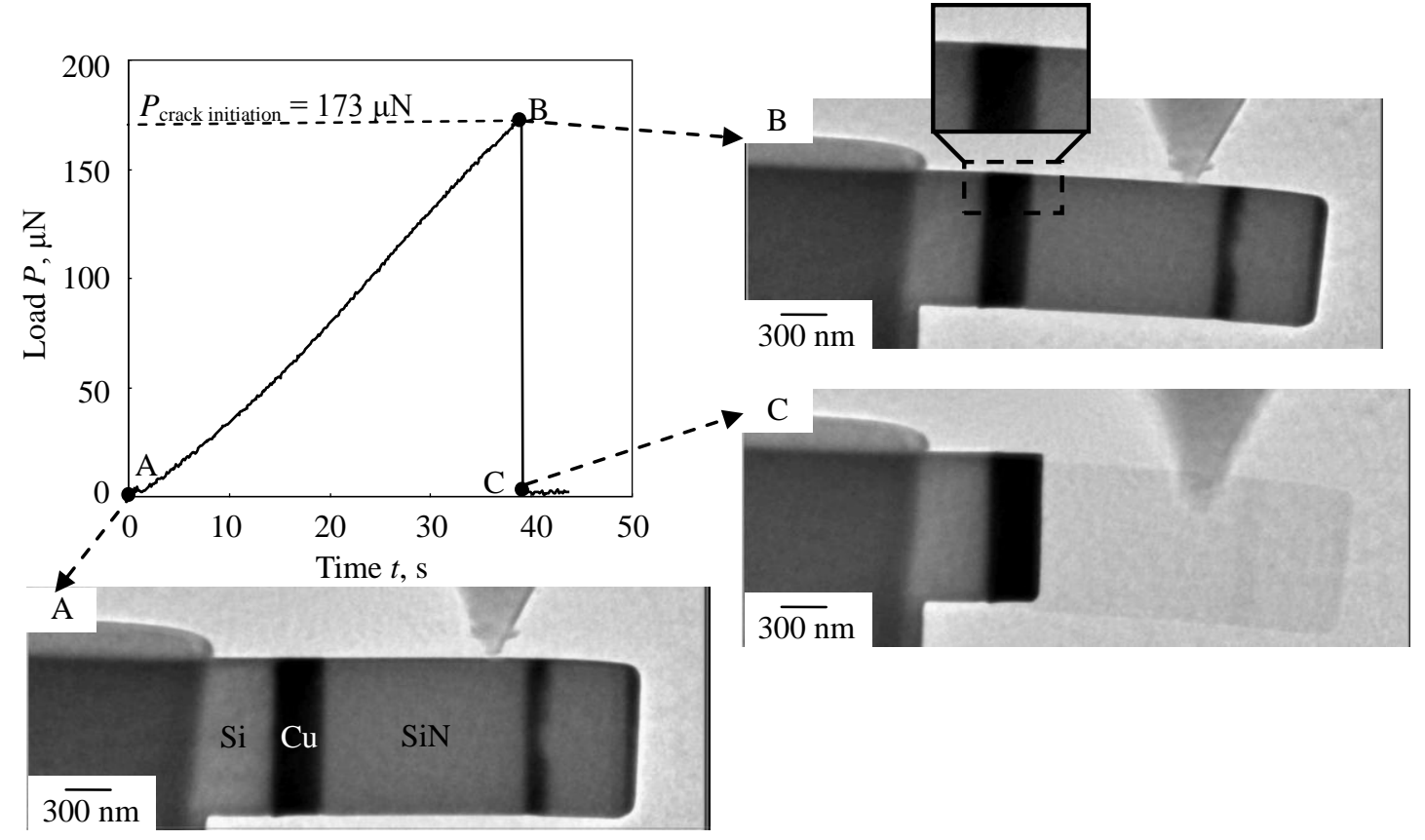

Fig. 5. Loading-time relationship and TEM images corresponding to points A-C. 
Table 4 Crack initiation load and bending stress at the interface edge of each specimen.

\begin{tabular}{|c|c|c|}
\hline Specimen & $\begin{array}{l}\text { Crack initiation load } \\
P_{\text {crack initiation }}(\mu \mathrm{N})\end{array}$ & $\begin{array}{l}\text { Bending stress at interface edge } \\
\sigma_{\mathrm{m}}(\mathrm{GPa})\end{array}$ \\
\hline 1 & 173 & 2.39 \\
\hline 2 & 39.4 & 2.96 \\
\hline 3 & 21.2 & 2.33 \\
\hline 4 & 16.2 & 3.68 \\
\hline
\end{tabular}

\subsection{Stress distribution along $\mathrm{Cu} / \mathrm{SiN}$ interface}

Considering the bending moment, the approximate normal stress at the interface edge is given by

$\sigma_{m}=\frac{P_{\text {crack initiation }} * L}{I} * \frac{h}{2}$

$I=\frac{h^{3} w}{12}$

where $L$ is the distance from the loading point to the $\mathrm{Cu} / \mathrm{SiN}$ interface edge (Table 1 ). The magnitude of $\sigma_{\mathrm{m}}$ is listed in Table 4, which indicates that the crack initiation is governed by the bending moment. However, it should be noted that Eq.(2) does not includes the influence of the interface and plasticity. It is well known that the stress concentrates near the bi-material interface edge without an initial crack.

Figure 6 shows the distribution of normal stress $\sigma$ along the $\mathrm{Cu} / \mathrm{SiN}$ interface near the edge $r$ at the crack initiation load, $P_{\text {crack initiation }}$, obtained from the FEM analysis. This $\sigma$ includes the influence of the interface and plasticity. This log-log graph shows a linear relationship between $\sigma$ and $r$ near the interface edge. Therefore, there is a singular stress field,

$\sigma=\frac{K_{\text {interface edge }}}{r^{\lambda}}$

where $K_{\text {interface edge }}$ is the stress intensity parameter that characterizes the intensity of the singular stress field near the $\mathrm{Cu} / \mathrm{SiN}$ interface edge, and $\lambda$ is the order of the stress singularity which depends on the material combination and the edge geometry. Here, as Fig. 6 shows the elasto - plastic stress distribution, $K_{\text {interface edge }}$ is the plastic stress intensity parameter near the interface edge. In this paper, the region until which the stress distribution departs $5 \%$ from that predicted by Eq. (3) is defined as the singular stress field. Figure 6 shows that the magnitude of the singular stress field is approximately $150 \mathrm{~nm}$ for Specimen 1 which is the largest specimen in this experiment. For Specimen 4 which is the smallest specimen in this study, the magnitude of the singular stress field is approximately $25 \mathrm{~nm}$. Figure 6 also shows that the normal stress for each specimen agree until the region which $r$ is approximately $25 \mathrm{~nm}$. Above this region, the normal stresses do not show good agreement. The magnitude of the singular stress field for each specimen is listed in Table 5 .

Table 6 shows the critical magnitude of the plastic stress intensity parameter, $K_{\text {interface edge (C), for each }}$ 
specimen. Regardless of the specimen dimensions, $K_{\text {interface edge (C) }}$ is substantially constant $(112 \mathrm{MPa} \cdot$ $\mathrm{m}^{0.179}$ ). Thus, in nanoscale specimen, the delamination crack initiation is govern by the singular stress field of approximately $25 \mathrm{~nm}$ near the interface edge.

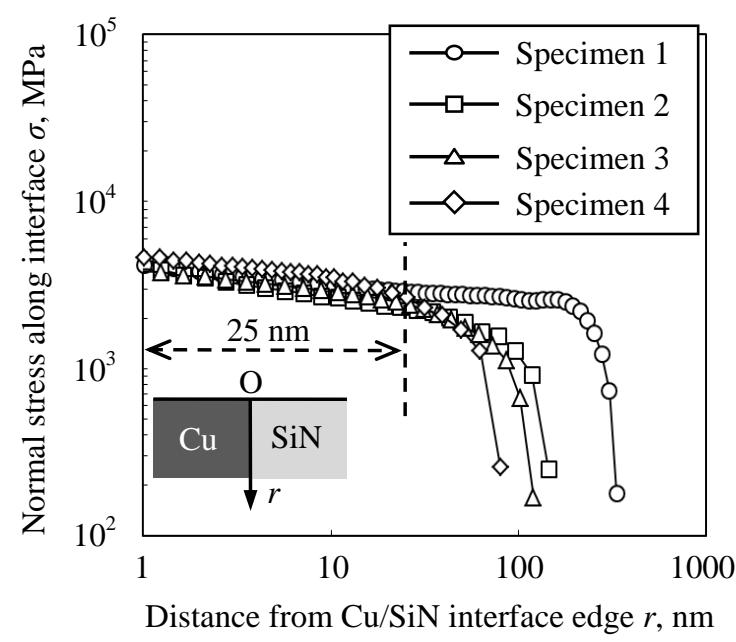

Fig. 6. Distribution of normal stress along the $\mathrm{Cu} / \mathrm{SiN}$ interface at crack initiation.

Table 5 Magnitude of singular stress field at the $\mathrm{Cu} / \mathrm{SiN}$ interface.

\begin{tabular}{ll}
\hline Specimen & $\begin{array}{l}\text { Magnitude of singular } \\
\text { stress field } \Lambda_{\mathrm{K}}(\mathrm{nm})\end{array}$ \\
\hline 1 & 150 \\
2 & 50 \\
3 & 45 \\
4 & 25 \\
\hline
\end{tabular}

Table 6 Critical magnitude of the plastic stress intensity parameter for each specimen.

\begin{tabular}{ll}
\hline Specimen & $\begin{array}{l}\text { Critical magnitude of the plastic } \\
\text { stress intensity parameter } \\
\end{array}$ \\
$K_{\text {interface edge }(\mathrm{C}),\left(\mathrm{MPa} \cdot \mathrm{m}^{\lambda}\right)}$ \\
\hline 1 & 123 \\
2 & 99 \\
3 & 101 \\
4 & 127 \\
\hline Average & 112 \\
\hline
\end{tabular}




\section{Conclusion}

In order to investigate the delamination crack initiation from an interfacial edge in the nanoscale component with the singular stress field, we conduct mechanical experiments using specimens with singular stress field on the nanometer scale at the $\mathrm{Cu} / \mathrm{SiN}$ interface. The results are summarized as follows:

(1) At the cantilever-specimens examined in this paper, a crack is initiated at the $\mathrm{Cu} / \mathrm{SiN}$ interface edge and instantaneously propagates along the $\mathrm{Cu} / \mathrm{SiN}$ interface.

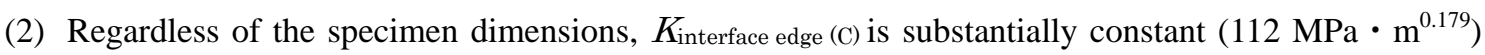
within the range which the magnitude of the singular stress field is approximately $25 \mathrm{~nm}$.

(3) In the nano-sized component, the delamination crack initiation is dominated by a nanoscale singular stress field near the interface edge.

\section{Acknowledgement}

This study was supported by JSPS KAKENHI Grant Numbers 21226005, 24686018 and 25000012.

\section{References}

[1] A.Gradin. A fracture criterion for edge-bonded bimaterial bodies. Journal of composite materials 1982;16:448-56.

[2] Zhixue Wu. Stress concentration analyses of bi-material bonded joints without in-plane stress singularities. International Journal of Mechanical Sciences 2008;50:641-8.

[3] D.B.Bogy. Edge bonded dissimilar orthogonal elastic wedges under normal and shear loading. Journal of Applied Mechanics 1968;35:460-6.

[4] Seiji Ioka, Keiji Masuda, Shiro Kubo. Singular stress field near the edge of interface of bonded dissimilar materials with an interlayer. International Journal of Solids and Structure 2007;44:6232-8.

[5] J.H.You, Y.Y.Yang. Behavior of stress singularities near the free edge of CFC/TZM bond interface under transient high heat flux loading. Fusion Engineering and Design 1998;38:331-42.

[6] J.R.Rice. Elastic fracture mechanics concepts for interfacial cracks. Journal of Applied Mechanics 1988;55:98-103.

[7] Pizhong Qiao, Jialai Wang, Mechanics and fracture of crack tip deformable bi-material interface. International Journal of Solids and Structures 2004;41:7423-44.

[8] S.T.Raveendra, P.K.Banerjee. Computation of stress intensity factors for interfacial cracks. Engineering Fracture Mechanics 1991;40:89-103.

[9] S.A.Hamoush, S.H.Ahmad. Mode I and mode II stress intensity factors for interfacial cracks in bi-material media. Engineering Fracture Mechanics 1989;33:421-7. 
[10] A.R.Akisanya, C.S.Meng, Initiation of fracture at the interface corner of bi-material joints. Journal of the Mechanics and Physics of Solids 2003;51:27-46.

[11] E.D.REEDY, JR, Intensity of the stress singularity at the interface corner between a bonded elastic and rigid layer. Engineering Fracture Mechanics 1990;36:575-83.

[12] D.Munz, Y.Y.Yang, Stresses near the edge of bonded dissimilar materials described by two stress intensity factor. International Journal of Fracture 1993;60:169-77.

[13] A.R.AKISANYA. Interfacial cracking from the free-edge of a long bi-material strip. International Journal of Solids and Structures 1997;34:1645-65.

[14] T.L.Becker Jr, J.M.McNaney, R.M.Cannon, R.O.Ritchie. Limitations on the use of the mixed-mode delaminating beam test specimen: Effects of the size of the region of K-dominance. Mechanics of Materials 1997;25:291-308.

[15] Takashi Sumigawa, Tetsuya Shishido, Tadashi Murakami, Takayuki Kitamura. Interface crack initiation due to nano-scale stress concentration. Materials Science and Engineering A 2010;527:4796-803.

[16] Takashi Sumigawa, Tadashi Murakami, Tetsuya Shishido, Takayuki Kitamura. Cu/Si interface fracture due to fatigue of copper film in nanometer scale. Materials Science and Engineering A 2010;527:6518-23. 